Reprinted from The ANALyst, the Journal of the Society for Analytical Chemistry,

January, 1966, Vol. 91, No. 1078.

INSTTIUUE YOOR

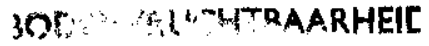

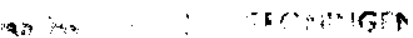

\title{
Apparatus for the Equal Distribution of Colour Reagent on Chromatograms Used for Quantitative Work
}

\author{
BY W. LOUWERSE \\ (Institute for Biological and Chemical Research on Field Crops and Herbage, \\ Wageningen, The Netherlands)
}

IN order to develop a colour on paper chromatograms the paper is usually sprayed with the reagent. This method is not very useful in quantitative work, as it is difficult to distribute the substance uniformly. In quantitative work on amino-acid chromatograms this method gave irregular results. To overcome the difficulty Toennies and Kolb ${ }^{1}$ pulled the amino-acid chromatogram through a solution of ninhydrin in acetone. As amino-acids are insoluble in acetone, running is prevented. In testing this method it appeared that the colouring of the amino-acids was irregular and some amino-acids such as $\gamma$-amino-n-butyric acid gave no colour at all. A better reagent is a 0.5 per cent. solution of ninhydrin in a water-saturated mixture of butanol - acetic acid, 93 to 7 , as used by Linskens, ${ }^{2}$ but this has the disadvantage that the amino-acids are slightly soluble in it and start to run when the paper is too wet. This is common with the so-called "dipping" technique, in which the paper is pulled quickly through the solution.

A method for using this reagent was developed in which a uniform distribution of the reagent is achieved without running of the amino-acids. As the technique proved to be successful a brief description is given.

\section{METHOD}

The chromatogram is pulled between two glass rollers, about $70 \mathrm{~cm}$ long and $2 \mathrm{~cm}$ in diameter. Both rollers are covered with "tubegauz" bandage.* The lower one, $\mathrm{C}$, dips in a trough, $\mathrm{A}$, filled

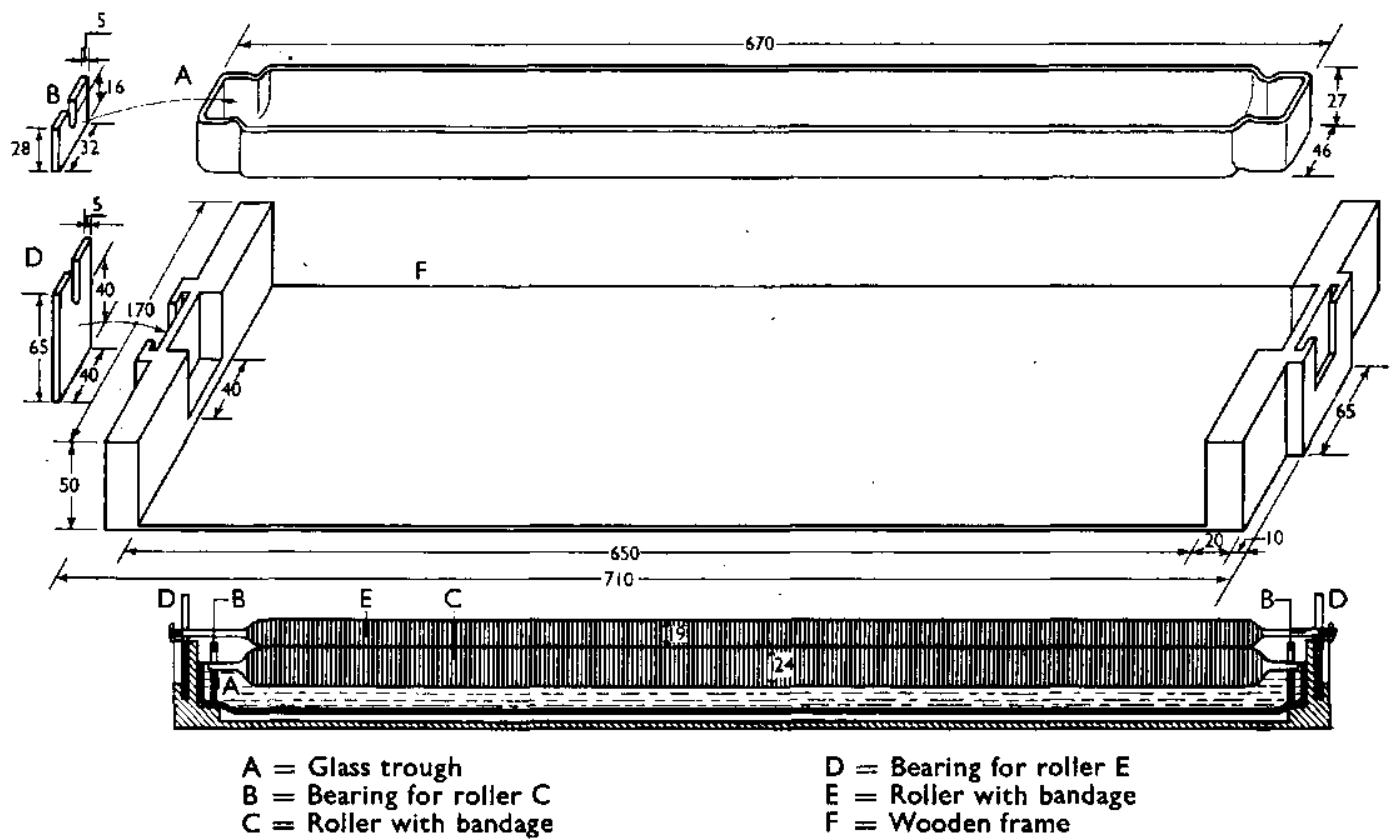

Fig. 1. Diagram of the apparatus. All dimensions are given in millimetres

* The Scholl Mfg. Co. Ltd., London, E.C.1. 
with the reagent (see Fig. 1); the upper roller, E, is filled with water, to make it heavier and so press more tightly against the other. Both rollers are suspended on horse-shoe shaped glass bearings, $B$ and $D$, so that they are free to move in a vertical direction. When the bearings and the rollers are placed in a wooden frame, F, the two rollers, covered with the bandage, just touch each other, while each rests in its own bearings. Further details and the exact dimensions (in $\mathrm{mm}$ ) are given in Fig. 1. The bandages around the two rollers are evenly wetted with the reagent by a few turns and the chromatogram is pulled through. The chromatogram becomes uniformly wetted, but the amount of reagent in the paper is so small that no running occurs and the spots can be located exactly. If the upper roller, $\mathrm{E}$, is not filled with water its weight $(\mathbf{1 5 0} \mathrm{g})$ is insufficient to ensure uniform wetting of the paper. When filled with water it weighs $250 \mathrm{~g}$ and gives good results. An extra loading up to $450 \mathrm{~g}$ does not affect the results. Papers other than Whatman No. 1 have not been examined for colouring and wet strength. The amount of reagent dispensed may depend on the roller weight, but is not critical as long as the paper becomes uniformly wetted.

\section{REFERENCES}

1. Toennies, G., and Kolb, J. J., Analyt. Chem., 1951, 23, 823.

2. Linskens, H. F., "Papierchromatographie in der Botanik," Springer-Verlag, Berin, 1955. 